\title{
Correction: Type V Collagen Induced Tolerance Suppresses Collagen Deposition, TGF- $\beta$ and Associated Transcripts in Pulmonary Fibrosis
}

Ragini Vittal, Elizabeth A. Mickler, Amanda J. Fisher, Chen Zhang, Katia Rothhaar, Hongmei Gu, Krista M. Brown, Amir Emtiazjoo, Jeremy M. Lott, Sarah B. Frye, Gerald N. Smith, George E. Sandusky, Oscar W. Cummings, David S. Wilkes

The eighth author's name is spelled incorrectly. The correct name is: Amir Emtiazjoo.

\section{Reference}

1. Vittal R, Mickler EA, Fisher AJ, Zhang C, Rothhaar K, Gu H, et al. (2013) Type V Collagen Induced Tolerance Suppresses Collagen Deposition, TGF- $\beta$ and Associated Transcripts in Pulmonary Fibrosis. PLoS ONE 8(10): e76451. https://doi.org/10.1371/journal.pone.0076451 PMID: 24204629

G OPENACCESS

Citation: Vittal R, Mickler EA, Fisher AJ, Zhang C, Rothhaar K, Gu H, et al. (2018) Correction: Type V Collagen Induced Tolerance Suppresses Collagen Deposition, TGF- $\beta$ and Associated Transcripts in Pulmonary Fibrosis. PLoS ONE 13(12): e0209107. https://doi.org/10.1371/journal.pone.0209107

Published: December 6, 2018

Copyright: @ 2018 Vittal et al. This is an open access article distributed under the terms of the Creative Commons Attribution License, which permits unrestricted use, distribution, and reproduction in any medium, provided the original author and source are credited. 